in vivo $34: 2469-2474(2020)$

doi:10.21873/invivo.12062

\title{
Demethoxycurcumin Inhibits In Vivo Growth of Xenograft Tumors of Human Cervical Cancer Cells
}

\author{
FU-SHIN CHUEH ${ }^{1}$, JIN-CHERNG LIEN ${ }^{2}$, YU-CHENG CHOU ${ }^{3,4}$, WEN-WEN HUANG ${ }^{5}$, \\ YI-PING HUANG ${ }^{6}$, JYE-YU HUANG ${ }^{5}$, JUNG-YU KUO ${ }^{5}$, WAN-NI HUANG ${ }^{5}$, \\ SHOU-YI SHENG ${ }^{5}$, HAO-YUN TUNG ${ }^{5}$, HUNG-YI CHEN ${ }^{2,7^{*}}$ and SHU-FEN PENG ${ }^{5,8^{*}}$ \\ ${ }^{I}$ Department of Food Nutrition and Health Biotechnology, Asia University, Taichung, Taiwan, R.O.C.; \\ ${ }^{2}$ Department of Pharmacy, China Medical University, Taichung, Taiwan, R.O.C.; \\ ${ }^{3}$ Department of Neurosurgery, Neurological Institute, \\ Taichung Veterans General Hospital, Taichung, Taiwan, R.O.C.; \\ ${ }^{4}$ Department of Neurological Surgery, Tri-Service General Hospital, \\ National Defense Medical Center, Taipei, Taiwan, R.O.C.; \\ ${ }^{5}$ Department of Biological Science and Technology, China Medical University, Taichung, Taiwan, R.O.C.; \\ ${ }^{6}$ Department of Physiology, College of Medicine, China Medical University, Taichung, Taiwan, R.O.C.; \\ ${ }^{7}$ Department of Pharmacy, China Medical University Beigang Hospital, Yunlin, Taiwan, R.O.C.; \\ ${ }^{8}$ Department of Medical Research, China Medical University Hospital, Taichung, Taiwan, R.O.C.
}

\begin{abstract}
Background/Aim: Demethoxycurcumin (DMC), a derivate of curcumin from natural plants, exerts antitumor effects on various human cancer cells in vitro and in vivo. Nevertheless, no reports have disclosed whether DMC can affect the growth of human cervical cancer cells in vivo. Therefore we investigated the antitumor effects of DMC on a HeLa cell xenograft model in nude mice in this study. Materials and Methods: Twenty-four nude mice were subcutaneously injected with HeLa cells. All mice were randomly divided into control, low-dose DMC (30 mg/kg), and high-dose DMC $(50 \mathrm{mg} / \mathrm{kg})$ groups and individual mice were treated intraperitoneally accordingly every 2 days. Results: DMC significantly reduced tumor weights and volumes of HeLa cell xenografts in mice, indicating the suppression of growth of xenograft tumors. Conclusion:
\end{abstract}

This article is freely accessible online.

*These Authors contributed equally to this work.

Correspondence to: Shu-Fen Peng, Ph.D., Department of Medical Research, China Medical University Hospital, No. 2, Yude Road, Taichung, 404, Taiwan. Tel: +886422053366 ext. 2506, Fax: +886 422053764, e-mail: t20811@mail.cmuh.org.tw; Hung-Yi Chen, Ph.D., Department of Pharmacy, China Medical University, No 91, Hsueh-Shih Road, Taichung, Taiwan. Tel: +886 422053366 ext. 5110, Fax: +886 422078083, e-mail: hungyi@ mail.cmu.edu.tw

Key Words: Demethoxycurcumin, DMC, human cervical cancer, HeLa cells, xenograft mice.
These effects and findings might provide evidence for investigating the potential use of DMC as an anti-cervical cancer drug in the future.

Cervical cancer is the seventh most common cancer globally and the fourth most common type of cancer in women $(1,2)$. In 2018, there were an estimated 567,000 new cases and 311,000 deaths from cervical cancer globally (3). About $80 \%$ of cervical cancer arises in developing countries (3). Among females, cervical cancer is the second most commonly diagnosed cancer and the third leading cause of cancer death in less developed countries $(4,5)$. In Taiwan, the 2017 annual report of the Ministry of Health and Welfare indicated that approximately four individuals per 100,000 die annually with cervical cancer, and it was the eighth cause of cancer-related death (6). Currently, surgery, radiotherapy, chemotherapy, and immunotherapy are four main treatment options for cervical cancer; however, the treatment of patients with cervical cancer depends on the cancer stage and tumor location according to diagnosis and characteristics of the patients $(7,8)$.

The incidence of cervical cancer is increasing worldwide. Chemotherapy is one of the strategies for treatment and it has been demonstrated to trigger effective response and improves overall survival in many patients. However, cancer may develop resistance to chemotherapies and lead to treatment failure $(9,10)$. Other side-effects of the current chemotherapy treatment of patients with cervical cancer are fatigue, nausea, vomiting, and diarrhea (11). Therefore, many studies have focused on finding and seeking new compounds from natural products for treating cervical cancer. 


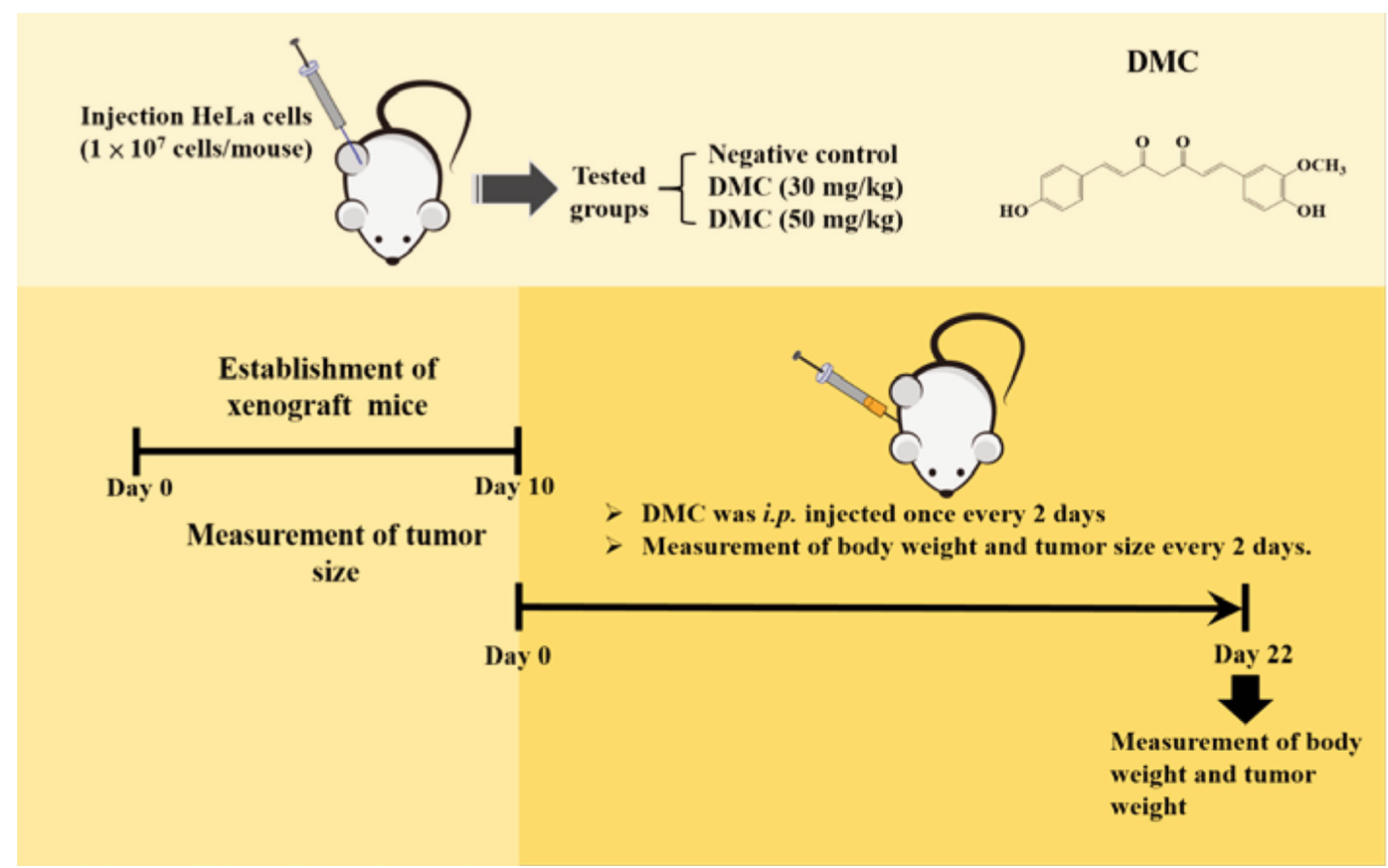

Figure 1. The experimental design for the demethoxycurcumin (DMC) treatments in human cervical HeLa cell-bearing mice. Each nude mouse was injected with $1 \times 10^{7} \mathrm{HeLa}$ cells. Animals were randomly divided into three different treatment groups $(n=8$ for each group; control (NC) and 30 $\mathrm{mg} / \mathrm{kg}$ and $50 \mathrm{mg} / \mathrm{kg}$ of DMC) when the tumor volume reached $100-120 \mathrm{~mm}^{3}$ in each mouse. DMC was administered every 2 days by intraperitoneal injection. All mice were sacrificed at 22 days after treatment.

Curcuminoids are found in Curcuma longa Linn. They are polyphenol compounds and include curcumin, demethoxycurcumin (DMC), and bisdemethoxycurcumin (BDMC) present at a ratio of 77:17:3, respectively (12). Curcumin has been widely used as natural food additive in Asian countries, especially in India and China $(13,14)$. DMC, a derivative of curcumin, is more chemically stable than curcumin (15) and induced cell apoptosis GBM 8401 human malignant glioma cells via mitochondria- and caspasedependent pathways (16). DMC significantly inhibited cell proliferation and metastasis activity, including cell migration and invasion in PC-3 human prostate cancer cells in vitro (17). It also induced cell apoptosis and DNA damage in NCI-H460 human lung cancer cells (18). DMC reduced cell viability and induced cell cycle arrest $\left(G_{2} / M\right)$ in A431 skin cancer cells and HaCaT human keratinocyte cells (19). In addition, DMC showed higher growth inhibition of glioblastoma stem cells than did temozolomide in vivo (20). Recently, we found that DMC induced cell apoptosis of human oral cancer cells via ROS- and mitochondrial-dependent pathway and cell autophagy (21). However, as far as we are aware, there is no report to show the effect of DMC on growth of cervical cancer cells in vivo. Therefore, we investigated the effects of DMC suppressed tumor growth of human cervical cancer HeLa cell xenograft in nude mice and results indicated DMC significantly inhibited tumor growth in vivo.

\section{Materials and Methods}

Test chemicals, reagents and culture medium. DMC, dimethyl sulfoxide (DMSO), and trypan blue were obtained from Sigma Chemical Co. (St. Louis, MO, USA). Dulbecco's modified Eagle's medium, fetal bovine serum (FBS), L-glutamine, and antibiotics (penicillin and streptomycin) were purchased from $\mathrm{GIBCO}^{\circledR /}$ Invitrogen Life Technologies (Grand Island, NY, USA). DMC was dissolved in DMSO before use.

Cell culture. HeLa human cervical cancer cell line was purchased from the Food Industry Research and Development Institute (Hsinchu, Taiwan, R.O.C.) and cultured based on the supplier's instructions. Cells were cultured in DMEM containing $10 \%$ FBS, 2 mM Lglutamine, $100 \mathrm{Units} / \mathrm{ml}$ penicillin, and $100 \mu \mathrm{g} / \mathrm{ml}$ streptomycin. Cells were grown in a $75 \mathrm{~cm}^{2}$ culture flasks under a humidified $5 \% \mathrm{CO}_{2}$ and $95 \%$ air at $37^{\circ} \mathrm{C}$ at 1 atmosphere as described previously (22).

Animals and treatments. Twenty-four athymic male mice (CAnN.Cg-Foxn $1^{n u} / \mathrm{CrlNarl}$ nude mice; six-week-old) were obtained from the National Laboratory Animal Center (Taipei, Taiwan, R.O.C.). All animals were used in this study according to the National Institutes of Health Guidelines for Animal Research. All animals were housed at the Animal Center of China Medical University (Taichung, Taiwan, ROC) and approved by the Institutional Animal Care and Use Committee of China Medical University (number: 106-asia-13). HeLa cells $\left(1 \times 10^{7}\right)$ were resuspended in $50 \mu \mathrm{l}$ of serum-free DMEM and then mixed with 50 $\mu l$ of Matrigel. The cell mixture was subcutaneously inoculated into 


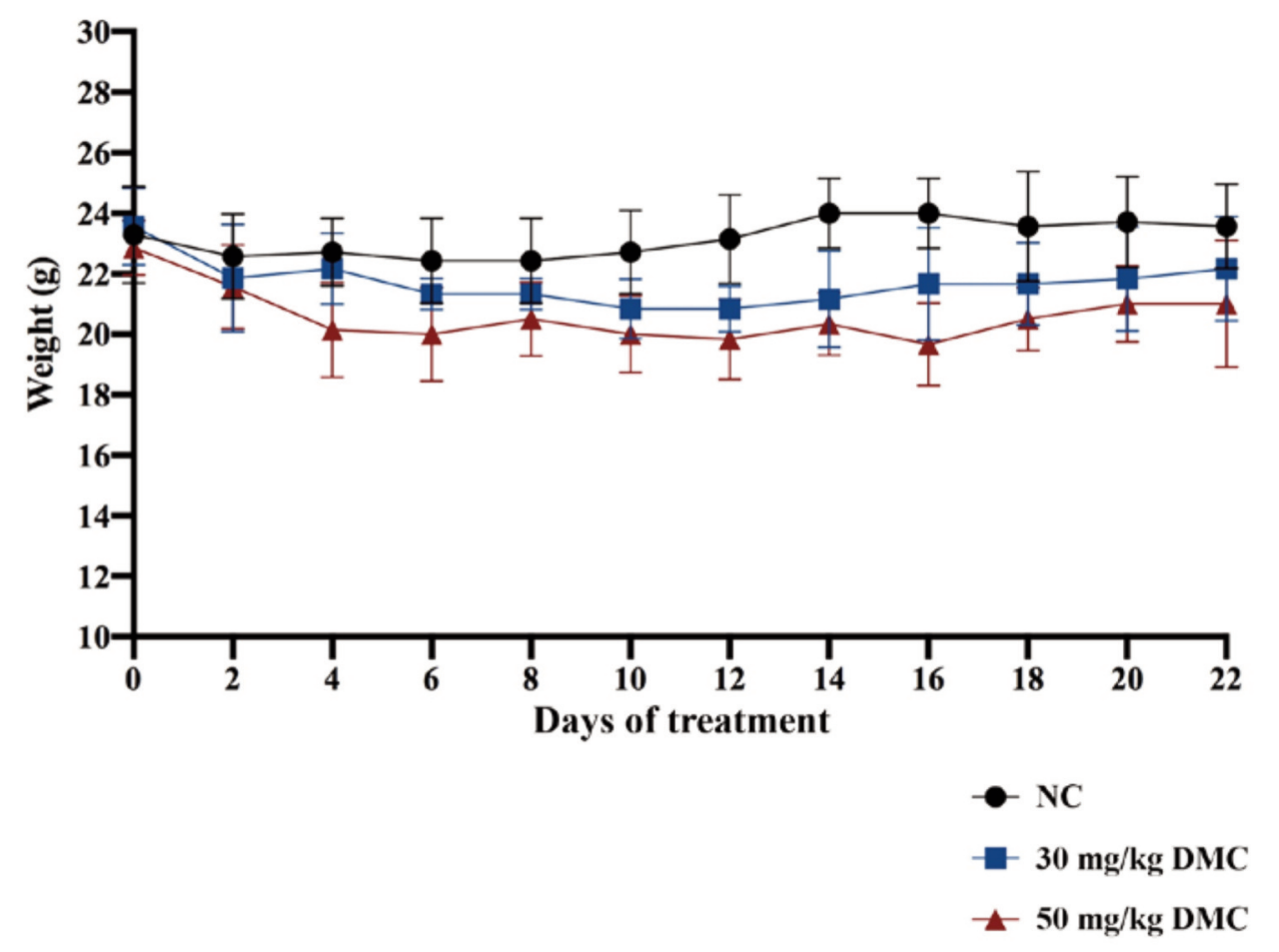

Figure 2. The effects of demethoxycurcumin (DMC) on the body weights of xenografts in HeLa cell-bearing mice. The body weights of control (NC) and DMC-treated $(30 \mathrm{mg} / \mathrm{kg}$ and $50 \mathrm{mg} / \mathrm{kg}$ ) mice were measured and recorded every 2 days for a total of 22 days and presented. The data are expressed as the mean \pm S.D.

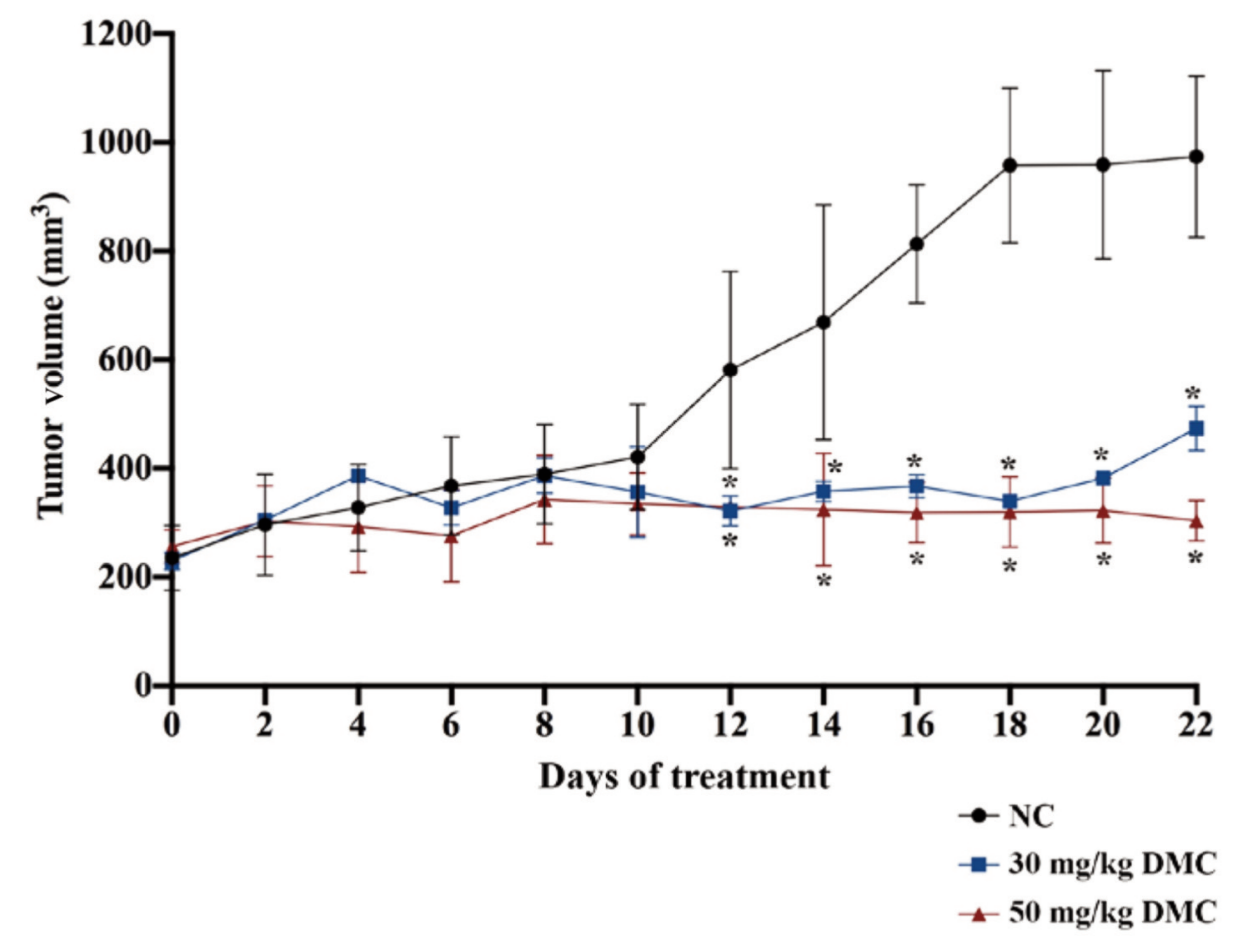

Figure 3. Antitumor evaluation of demethoxycurcumin (DMC) in xenografts in HeLa cell-bearing mice. Tumor volume was individually measured in control (NC) and DMC-treated $\left(30 \mathrm{mg} / \mathrm{kg}\right.$ and $50 \mathrm{mg} / \mathrm{kg}$ ) mice every 2 days. ${ }^{*}$ Significantly different from the control at $p<0.05$. The data are expressed as the mean \pm S.D. 
A

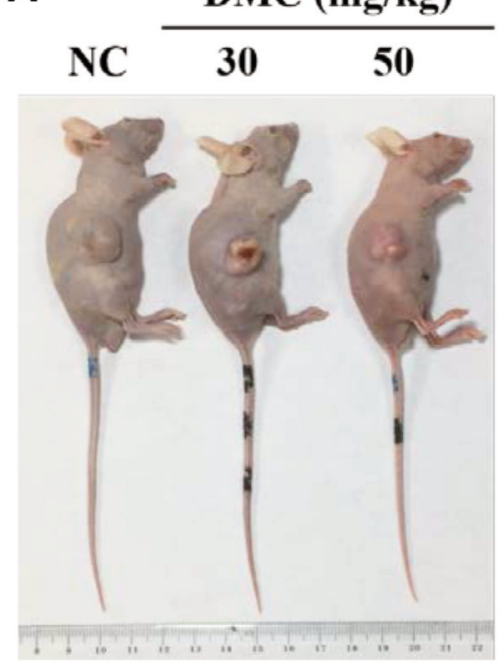

B

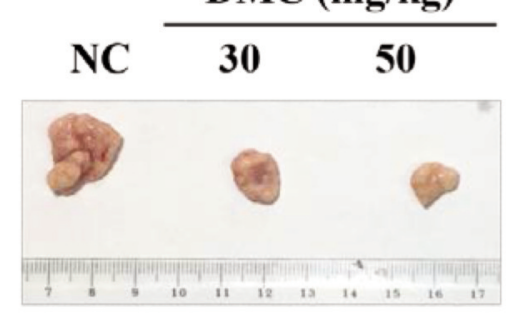

C

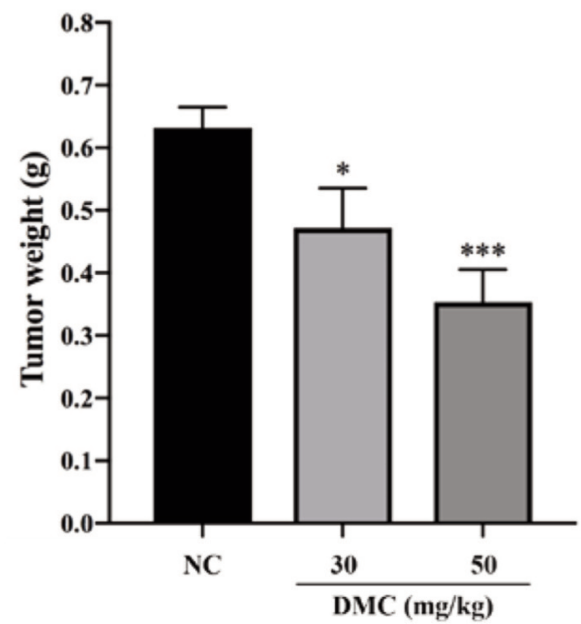

Figure 4. Antitumor evaluation of demethoxycurcumin (DMC) in xenografts in HeLa cell-bearing mice. A: The tumor growth of each mouse was monitored and representative tumors on control (NC) and DMC-treated (30 $\mathrm{mg} / \mathrm{kg}$ and $50 \mathrm{mg} / \mathrm{kg}$ ) mice from the three groups after 22 days of treatment are presented. B: Representative tumors from three groups are shown. C: DMC at both doses (30 and $50 \mathrm{mg} / \mathrm{kg})$ significantly suppressed tumor growth when compared to the control group. Significantly different from the control at $* p<0.05$ and $* * * p<0.001$. The data are expressed as the mean \pm S.D.

the right hind flank of nude mice. Tumor growth in each mouse was monitored by a digital caliper and calculated with the equation: tumor volume $=0.523 \times$ length $\times$ width $^{2}(23)$.

All animals were randomly divided into three different treatment groups (control, $30 \mathrm{mg} / \mathrm{kg}$ DMC, and $50 \mathrm{mg} / \mathrm{kg}$ DMC; $\mathrm{n}=8$ for each group) when the tumor volume reached $100-120 \mathrm{~mm}^{3}$ in each mouse. The control group animals were treated with $45 \mu \mathrm{l}$ phosphate-buffered solution (PBS) plus $5 \mu$ l DMSO by intraperitoneal (i.p.) injection every 2 days for 22 days. Experimental groups were treated with $30 \mathrm{mg} / \mathrm{kg}$ or $50 \mathrm{mg} / \mathrm{kg}$ of DMC by i.p. injection every 2 days for 22 days. The body weight and tumor volume of each mouse from each group were measured after treatment. At the end of treatment, all mice were sacrificed for isolating the tumor, as described previously (24). Individual tumor weights of mice from three groups were recorded every 2 days. The flowchart of the experimental design is displayed in Figure 1.

Statistical analysis. All data from the three groups are presented as the mean \pm standard error. For the comparison between DMC-treated and control groups, one-way ANOVA with Newman-Keuls multicomparison test was used. Differences between the experimental groups and the control at $p<0.05$ or less were recognized to be significant.

\section{Results}

DMC affected the body weight of animals with HeLa cell xenograft. As shown in Figure 2, there was no significant difference in body weight among the three groups (control, $30 \mathrm{mg} / \mathrm{kg}$ and $50 \mathrm{mg} / \mathrm{kg}$ of DMC), which reflected no signs of acute or delayed toxicity of DMC in the examined mice.

DMC inhibited tumor xenograft growth of HeLa cells. After treatment for 12 days, DMC significantly diminished tumor volume when compared to the control (0.1\% DMSO/PBS) group. Tumor volume was significantIy lower after 22-day DMC treatment compared to the control (Figure 3).

After treatment, all mice from each group were sacrificed and representative mice were photographed and are shown in Figure 4A. Subsequently, the individual tumor was collected from each mouse and representative tumors are presented in Figure 4B. The final tumor weight was measured and recorded in Figure 4C.

Both doses of DMC (30 and $50 \mathrm{mg} / \mathrm{kg}$ ) significantly reduced the tumor volume in comparison with the control group, and DMC at a high dose $(50 \mathrm{mg} / \mathrm{kg})$ resulted in greater reduction of tumor volume than did the low dose (30 mg/kg) (Figure 4B). Similarity, both DMC treatments also significantly diminished the tumor weights in comparison with the control group, with high-dose DMC more greatly reducing the tumor weight than the low dose (Figure 4C).

\section{Discussion}

Currently, the preventative and therapeutic protocols for cervical cancer depended upon the stage of cancer, and human papillomavirus vaccines and Pap screening have been shown to be useful in preventing or detecting pre-cancerous lesions, respectively $(25,26)$. Typical clinical treatment of patients with cervical cancer includes surgery, radiation, and cisplatin-based chemotherapy (27). Unfortunately, the development of drug resistance is common. Numerous studies have attempted to focus on finding new approaches 
or new compounds from natural products to reduce drug toxicity and overcome resistance.

In the present study, we found that DMC at 30 and $50 \mathrm{mg} / \mathrm{kg}$ significantly reduced tumor volume (Figure 3) and tumor weight (Figure 4C) without adverse effects on body weight of mice. This supports findings of Ni et al. for the effects of another derivative of curcumin on subcutaneous xenograft tumors in human cervical HeLa cell-bearing mice in vivo (28, 29). These findings are also in agreement with previous study on SAS human oral cancer cell xenografts in nude mice (29). A decrease of body weight is an important marker in evaluating whether or not agents induce cytotoxic effects in vivo.

DMC is attractive for its antitumor effects on different mouse models of human cancer. The therapeutic potential of DMC was investigated in A549 human lung cancer cell xenograft mouse model (30). DMC inhibited tumor growth more effectively than temozolomide in an orthotopic glioblastoma model (31). Further study of co-treatment of DMC and temozolomide showed that DMC at a low dose enhanced the sensitivity of glioma cells to temozolomide in vitro but that at high dose presented greater effects on glioblastoma cells in vitro and in vivo compared with temozolomide treatment alone (32).

We found that DMC significantly suppressed the size and weight tumor from HeLa cell xenografts in nude mice in vivo and these findings are also consistent with reports in xenograft mouse models of glioma and lung cancer. This study is the first to show that DMC has anticervical tumor potential in an animal model in vivo.

Previous study by our groups has indicated that DMC had potent anti-metastasis effects on HeLa cells in vitro (4). Recently, we also demonstrated that gefitinib combined with DMC treatment in nude mice bearing SAS human oral cancer cell xenografts significantly reduced the tumor weight and volume, and did not affect the total body weight (29). Co-treatment with DMC and temozolomide was shown to have synergistic activity in the induction of cell apoptosis and the inhibition of cell proliferation in glioblastoma multiforme cells (32). Investigations regarding the molecular mechanism of DMC are needed.

In conclusion, DMC significantly diminished the tumor weights, size, and volumes of HeLa xenograft tumors in vivo. These results indicate that DMC can be considered as a potential drug for cervical cancer.

\section{Conflicts of Interest}

The Authors confirm that there are no conflicts of interest.

\section{Authors' Contributions}

Study conception and design: FSC, HYC and SFP; Acquisition of data: FSC, JYH, JYK, WNH, SYS and HYT; Analysis and interpretation of data: FSC, JCL, YCC and WWH; Drafting of manuscript: FSC, HYC and SFP; Critical revision: FSC, HYC and SFP All Authors discussed the results and commented on the article.

\section{Acknowledgements}

This work was supported from a research grant from Ministry of Science and Technology, Taipei, Taiwan [MOST 107-2635-B-468-002 -] and China Medical University Hospital [grant nos. DMR-108-108].

\section{References}

1 Aziz H, Iqbal H, Mahmood H, Fatima S, Faheem M, Sattar AA, Tabassum S, Napper S, Batool S and Rasheed N: Human papillomavirus infection in females with normal cervical cytology: Genotyping and phylogenetic analysis among women in Punjab, Pakistan. Int J Infect Dis 66: 83-89, 2018. PMID: 29138009. DOI: 10.1016/j.ijid.2017.11.009

2 Nama V, Angelopoulos G, Twigg J, Murdoch JB, Bailey J and Lawrie TA: Type II or type III radical hysterectomy compared to chemoradiotherapy as a primary intervention for stage IB2 cervical cancer. Cochrane Database Syst Rev 10: Cd011478, 2018. PMID: 30311942. DOI: 10.1002/14651858.CD011478. pub2

3 Bray F, Ferlay J, Soerjomataram I, Siegel RL, Torre LA and Jemal A: Global cancer statistics 2018: GLOBOCAN estimates of incidence and mortality worldwide for 36 cancers in 185 countries. CA Cancer J Clin 68: 394-424, 2018. PMID: 30207593. DOI: $10.3322 /$ caac. 21492

4 Torre LA, Bray F, Siegel RL, Ferlay J, Lortet-Tieulent J and Jemal A: Global cancer statistics, 2012. CA Cancer J Clin 65: 87-108, 2015. PMID: 25651787. DOI: $10.3322 / \mathrm{caac} .21262$

5 Chabeda A, van Zyl AR, Rybicki EP and Hitzeroth II: Substitution of human papillomavirus type 16 L2 neutralizing epitopes into L1 surface loops: The effect on virus-like particle assembly and immunogenicity. Front Plant Sci 10: 779, 2019. PMID: 31281327. DOI: 10.3389/fpls.2019.00779

6 Welfare MoHa: 2018 Taiwan Health and Welfare Report, 2019. Available at: https://www.mohw.gov.tw/cp-137-47558-2.html

7 Beyranvand Nejad E, Welters MJ, Arens R and van der Burg SH: The importance of correctly timing cancer immunotherapy. Expert Opin Biol Ther 17: 87-103, 2017. PMID: 27802061. DOI: $10.1080 / 14712598.2017 .1256388$

8 Wang R, Pan W, Jin L, Huang W, Li Y, Wu D, Gao C, Ma D and Liao S: Human papillomavirus vaccine against cervical cancer: Opportunity and challenge. Cancer Lett 471: 88-102, 2020. PMID: 31812696. DOI: 10.1016/j.canlet.2019.11.039

9 Housman G, Byler S, Heerboth S, Lapinska K, Longacre M, Snyder N and Sarkar S: Drug resistance in cancer: an overview. Cancers 6: 1769-1792, 2014. PMID: 25198391. DOI: 10.3390/ cancers6031769

10 Holohan C, Van Schaeybroeck S, Longley DB and Johnston PG: Cancer drug resistance: an evolving paradigm. Nat Rev Cancer 13: 714-726, 2013. PMID: 24060863. DOI: $10.1038 / \mathrm{nrc} 3599$

11 Li S, Hu T, Chen Y, Zhou H, Li X, Cheng X, Yang R, Wang S, Xie $X$ and Ma D: Adjuvant chemotherapy, a valuable alternative option in selected patients with cervical cancer. PLoS One 8: e73837, 2013. PMID: 24058496. DOI: 10.1371/journal.pone. 0073837 
12 Chen Y, Lu Y, Lee RJ and Xiang G: Nano encapsulated curcumin: and its potential for biomedical applications. Int J Nanomedicine 15: 3099-3120, 2020. PMID: 32431504. DOI: 10.2147/ijn.S210320

13 Jayaprakasha GK, Jagan Mohan Rao L and Sakariah KK: Chemistry and biological activities of $C$. longa. Trends Food Sci Technol 16: 533-548, 2005. DOI: 10.1016/j.tifs.2005.08.006

14 Hatcher H, Planalp R, Cho J, Torti FM and Torti SV: Curcumin: from ancient medicine to current clinical trials. Cell Mol Life Sci 65: 1631-1652, 2008. PMID: 18324353. DOI: $10.1007 /$ s00018-008-7452-4

15 Tamvakopoulos C, Dimas K, Sofianos ZD, Hatziantoniou S, Han Z, Liu ZL, Wyche JH and Pantazis P: Metabolism and anticancer activity of the curcumin analogue, dimethoxycurcumin. Clin Cancer Res 13: 1269-1277, 2007. PMID: 17317839. DOI: 10.1158/1078-0432.ccr-06-1839

16 Huang TY, Hsu CW, Chang WC, Wang MY, Wu JF and Hsu YC: Demethoxycurcumin retards cell growth and induces apoptosis in human brain malignant glioma GBM 8401 cells. Evid Based Complement Alternat Med 2012: 396573, 2012. PMID: 22454662. DOI: $10.1155 / 2012 / 396573$

$17 \mathrm{Ni} \mathrm{X}$, Zhang A, Zhao Z, Shen Y and Wang S: Demethoxycurcumin inhibits cell proliferation, migration and invasion in prostate cancer cells. Oncol Rep 28: 85-90, 2012. PMID: 22552297. DOI: $10.3892 /$ or.2012.1783

18 Ko YC, Lien JC, Liu HC, Hsu SC, Ji BC, Yang MD, Hsu WH and Chung JG: Demethoxycurcumin induces the apoptosis of human lung cancer NCI-H460 cells through the mitochondrialdependent pathway. Oncol Rep 33: 2429-2437, 2015. PMID: 25813094. DOI: 10.3892/or.2015.3865

$19 \mathrm{Wu}$ Y, Zhang P, Yang H, Ge Y and Xin Y: Effects of demethoxycurcumin on the viability and apoptosis of skin cancer cells. Mol Med Rep 16: 539-546, 2017. PMID: 28586041. DOI: 10.3892/mmr.2017.6666

20 Leng L, Zhong X, Sun G, Qiu W and Shi L: Demethoxycurcumin was superior to temozolomide in the inhibition of the growth of glioblastoma stem cells in vivo. Tumour Biol 37: 15847-15857, 2016. PMID: 27757851. DOI: 10.1007/s13277-016-5399-x

21 Hsiao YT, Kuo CL, Chueh FS, Liu KC, Bau DT and Chung JG: Curcuminoids induce reactive oxygen species and autophagy to enhance apoptosis in human oral cancer cells. Am J Chin Med 46: 1145-1168, 2018. PMID: 29976081. DOI: 10.1142/ s0192415x1850060x

22 Lin CH, Peng SF, Chueh FS, Cheng ZY, Kuo CL and Chung JG: The ethanol crude extraction of Cyperus Rotundus regulates apoptosis-associated gene expression in HeLa human cervical carcinoma cells in vitro. Anticancer Res 39: 3697-3709, 2019. PMID: 31262896. DOI: 10.21873/anticanres.13518

23 Della Peruta M, Badar A, Rosales C, Chokshi S, Kia A, Nathwani D, Galante E, Yan R, Arstad E, Davidoff AM, Williams R, Lythgoe MF and Nathwani AC: Preferential targeting of disseminated liver tumors using a recombinant adeno-associated viral vector. Hum Gene Ther 26: 94-103, 2015. PMID: 25569358. DOI: 10.1089/hum.2014.052
24 Wu SH, Bau DT, Hsiao YT, Lu KW, Hsia TC, Lien JC, Ko YC, Hsu WH, Yang ST, Huang YP and Chung JG: Bufalin induces apoptosis in vitro and has antitumor activity against human lung cancer xenografts in vivo. Environ Toxicol 32: 1305-1317, 2017. PMID: 27444971. DOI: $10.1002 /$ tox.22325

25 Ronco G and Segnan N: HPV testing for primary cervical cancer screening. Lancet 370: 1740-1742, 2007. PMID: 17919717. DOI: $10.1016 / \mathrm{s} 0140-6736(07) 61480-9$

26 Gillison ML, Chaturvedi AK and Lowy DR: HPV prophylactic vaccines and the potential prevention of noncervical cancers in both men and women. Cancer 113: 3036-3046, 2008. PMID: 18980286. DOI: $10.1002 /$ cncr.23764

27 Janicek MF and Averette HE: Cervical cancer: prevention, diagnosis, and therapeutics. CA Cancer J Clin 51: 92-114; quiz 115-118, 2001. PMID: 11577486. DOI: 10.3322/canjclin.51.2.92

$28 \mathrm{Ni}$ WY, Lu HF, Hsu SC, Hsiao YP, Liu KC, Liu JY, Ji BC, Hsueh SC, Hung FM, Shang HS and Chung JG: Phenethyl isothiocyanate inhibits in vivo growth of subcutaneous xenograft tumors of human malignant melanoma A375.S2 cells. In Vivo 28: 891-894, 2014. PMID: 25189905.

29 Hsiao YT, Kuo CL, Lin JJ, Huang WW, Peng SF, Chueh FS, Bau DT and Chung JG: Curcuminoids combined with gefitinib mediated apoptosis and autophagy of human oral cancer SAS cells in vitro and reduced tumor of SAS cell xenograft mice in vivo. Environ Toxicol, 2018. PMID: 29717538. DOI: 10.1002/ tox. 22568

30 Huang WT, Larsson M, Wang YJ, Chiou SH, Lin HY and Liu DM: Demethoxycurcumin-carrying chitosan-antibody core-shell nanoparticles with multitherapeutic efficacy toward malignant A549 lung tumor: from in vitro characterization to in vivo evaluation. Mol Pharm 12: 1242-1249, 2015. PMID: 25760774. DOI: $10.1021 / \mathrm{mp} 500747 \mathrm{w}$

31 Shi L and Sun G: DMC is not better than TMZ on intracranial anti-glioma effects. J Cell Biochem 119: 6057-6064, 2018. PMID: 29575236. DOI: $10.1002 /$ jcb. 26803

32 Shi L and Sun G: Low-dose DMC significantly enhances the effect of TMZ on glioma cells by targeting multiple signaling pathways both in vivo and in vitro. Neuromolecular Med 17: 431-442, 2015. PMID: 26458914. DOI: 10.1007/s12017-015$8372-8$
Received May 28, 2020

Revised June 23, 2020

Accepted June 24, 2020 